\title{
Familial aortic dissection
}

INSERM

\section{Source}

INSERM. (1999). Orphanet: an online rare disease and orphan drug data base. Familial aortic dissection. ORPHA:229

Familial aortic dissection is the term used to describe rupture of the aortic wall at the level of the media, resulting in the formation of a false channel and deviation of part of the aortic flux. Familial predisposition to thoracic aortic aneurysms and type A dissections (concerning the ascending aorta and/or the aortic arch) has been demonstrated in around $19 \%$ of patients presenting with thoracic aortic dissections and several loci have been identified so far (16p12.2-p13.13, 3p24-25). This predisposition is transmitted in an autosomal dominant manner. 